\title{
Cross-Cultural Analysis of Social Network Services in Japan, Korea, and the USA
}

\author{
Aaron Marcus and Niranjan Krishnamurthi \\ Aaron Marcus and Associates, Inc., \\ 1196 Euclid Avenue, Suite 1F, Berkeley, CA, 94708 USA \\ Aaron.Marcus@AMandA.com, Niranjan.Krishnamurthi@AMandA.com
}

\begin{abstract}
The techniques of cross-cultural analysis of Websites based on culture models are used to examine user-interface components (the metaphors, mental models, navigation, interaction, and appearance) of social networking sites in three countries. The authors note and evaluate patterns of similarity and difference in the Website designs that seem to link social networking sites by culture dimensions.
\end{abstract}

Keywords: appearance, China, culture, culture model, design, interaction, interface, Japan, Korea, language, mental model, metaphor, navigation, network,social, user.

\section{Introduction}

Social networking services (SNSs) are online communities that focus on bringing together people with similar interests or who are interested in exploring the interests and activities of others. SNSs have come a long way since the initial efforts of computer-mediated social networking such as USENET, LISTSERV and Bulletin Board Services. Today, there are numerous SNSs that cater to audiences around the globe and they are fast becoming a staple of online consumer activity. What is interesting to note, however, is that none of these sites are equally popular across cultures. The fact that MySpace is very popular in the USA, with about $74 \%$ of the market share 3 despite its famously cluttered layout but only captures $2.9 \%$ of the Japanese market share 14 could be attributed to differences in American and Japanese culture. There may be MySpace features that are so appealing to Americans as to forgive its bad design while the same may not hold true for Japanese users.

Using previous work by one of the authors as a guide, 9 and 8, this paper seeks to analyze differences and similarities of user-interface (UI) design for SNSs from Japan, South Korea, and the USA in order to understand to what extent the designs seem to exhibit patterns of difference and similarities that relate to corresponding cultural differences and similarities.

A fundamental basis of this paper and several others cited is Geert Hofstede's model of five cultural dimensions 4 , in which culture is exhibited by behaviors, heroes/heroines, signs, and values, and each country is assumed to have a dominant culture. See Figure 1 for a comparison of the cultures/countries studied in this paper. Another important aspect considered in this paper is the concept of user-interface components 10, which are metaphors, mental models, navigation, interaction and appearance. 


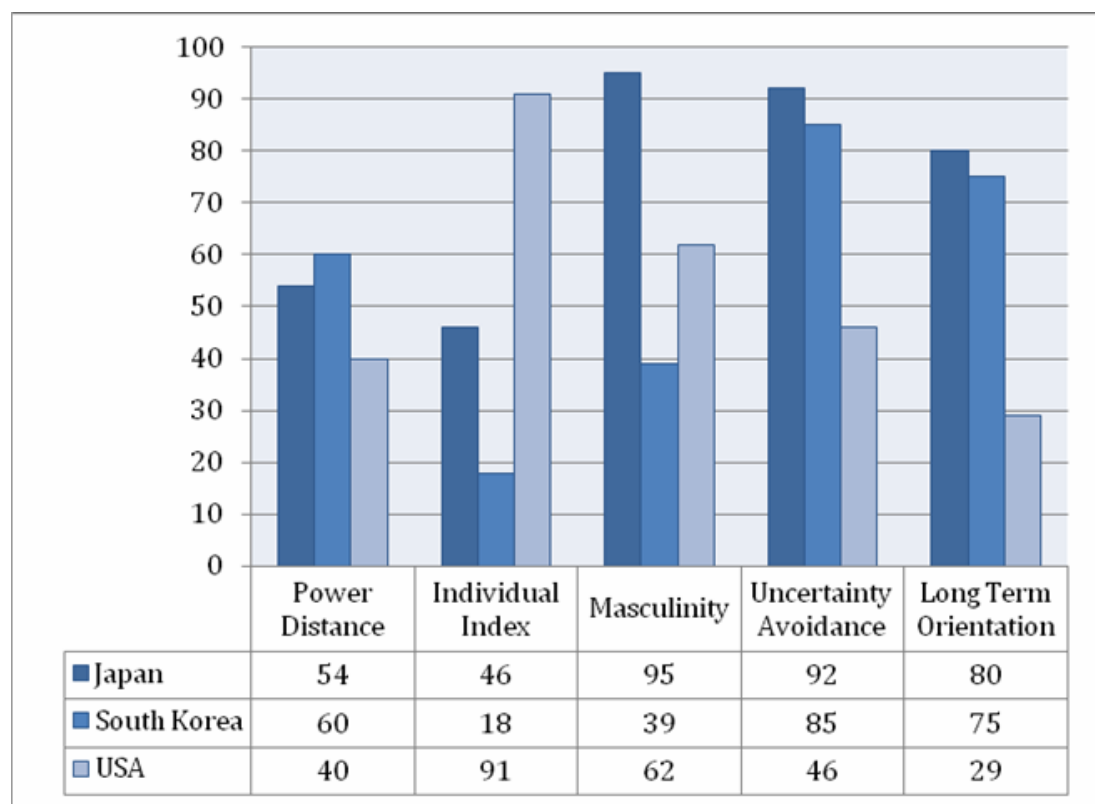

Fig. 1. Comparison of 5 typical cultural dimensions as explained by Geert Hofstede 4. Each dimension derives from a study of participants in 74 countries.

Combining Hofstede's cultural dimensions with the five user-interface components, a paper by Marcus and Baumgartner 8 analyzed 25 possible areas to evaluate how a company's corporate Website seems localized to a specific culture and found several observable patterns that were typical to certain cultures. Another work with the same principles as 8 is a tutorial presentation by the authors' firm 7, which analyzed the cultural differences between mobile platforms developed for Western cultures such as the United States and Europe and those developed for Eastern cultures such as Japan, South Korea and Taiwan.

This initial analysis attempts to use the methods proposed by Marcus and Baumgartner 8 to observe and analyze patterns that may be distinguished by culture.

\section{Methodology}

To analyze the cultural differences in SNSs, the authors' firm compiled a list of 39 seemingly well-known SNSs from Japan, South Korea, and the USA (one project assistant collecting sample sites was from Japan, and one was from South Korea). The team divided the SNSs into four categories based on the site's apparent main objective: fostering business relationships, sharing music and videos, sharing photos, and appealing to a youth market. In order to keep to the modest effort and time available for this project, the team considered only a select number of pages to visit for each SNS: 
- First Page: Typically an introduction to the services provided to members and nonmembers by the SNS. On some sites, the first page is also where the user signs into his or her account.

- Sign-up Page: The sign-up page allows a user to join the SNS. Usually, the user enters some amount of private information and creates a unique identification (ID) that will be used to identify him/herself on the site. This page is also where the user creates a personal password to ensure that access to his/her membership remains secure.

- Sign-in Page: On SNSs that do not integrate the sign-in dialogue into the first page, there is a unique page that allows users to enter his/her site ID and password to enter the members-only area of the SNS.

- Home Page: The homepage is the first page the user sees after signing in. On the home page, the user can access all the main elements of the SNS such as chat, messaging, blogging, photo sharing, search, etc.

Table 1. Summary of features analyzed on selected SNS pages. Note: CAPTCHA test cited in the table stands for "Completely Automated Public Turing test to tell Computers and Humans Apart".

\begin{tabular}{|c|c|c|c|}
\hline First Page & Home Page & Sign-up Page & Sign-in Page \\
\hline $\begin{array}{l}\text { Cuteness in } \\
\text { design }\end{array}$ & $\begin{array}{l}\text { Cuteness in } \\
\text { design }\end{array}$ & $\begin{array}{l}\text { Display of site } \\
\text { benefits }\end{array}$ & $\begin{array}{l}\text { Location of } \\
\text { sign-in } \\
\text { link/box on } \\
\text { first page }\end{array}$ \\
\hline $\begin{array}{l}\text { Number of } \\
\text { advertisements }\end{array}$ & $\begin{array}{l}\text { Number of } \\
\text { advertisements }\end{array}$ & $\begin{array}{l}\text { User identity } \\
\text { authentication }\end{array}$ & $\begin{array}{l}\text { Prominent } \\
\text { sign-in } \\
\text { link/box on } \\
\text { first page }\end{array}$ \\
\hline $\begin{array}{l}\text { Symmetrical } \\
\text { layout }\end{array}$ & $\begin{array}{l}\text { Symmetrical } \\
\text { layout }\end{array}$ & $\begin{array}{l}\text { CAPTCHA } \\
\text { test } 2\end{array}$ & $\begin{array}{l}\text { Use of sepa- } \\
\text { rate page for } \\
\text { sign-in }\end{array}$ \\
\hline $\begin{array}{l}\text { Simplicity in } \\
\text { design }\end{array}$ & $\begin{array}{l}\text { Simplicity in } \\
\text { design }\end{array}$ & $\begin{array}{l}\text { Type of privacy } \\
\text { statement }\end{array}$ & Use of icons \\
\hline Use of icons & Use of icons & Use of icons & \\
\hline $\begin{array}{l}\text { Public display } \\
\text { of private } \\
\text { member pho- } \\
\text { tos }\end{array}$ & $\begin{array}{l}\text { Display of } \\
\text { other members }\end{array}$ & & \\
\hline $\begin{array}{l}\text { Public display } \\
\text { of member } \\
\text { directory }\end{array}$ & $\begin{array}{l}\text { Display of } \\
\text { friends }\end{array}$ & & \\
\hline $\begin{array}{l}\text { Number of } \\
\text { links }\end{array}$ & $\begin{array}{l}\text { Number of } \\
\text { links }\end{array}$ & & \\
\hline $\begin{array}{l}\text { Type of colors } \\
\text { used }\end{array}$ & $\begin{array}{l}\text { Type of colors } \\
\text { used }\end{array}$ & & \\
\hline $\begin{array}{l}\text { Slogan uncer- } \\
\text { tainty }\end{array}$ & Customization & & \\
\hline $\begin{array}{l}\text { Selling expla- } \\
\text { nation }\end{array}$ & Personalization & & \\
\hline
\end{tabular}


The details examined on each page were restricted to items that were readily observable. As Table 1 indicates, not all features apply to every page. For example, the use of identity verification is only applicable during the sign-up process. Many of the features are quantified as simple yes/no questions. Some other features, such as the number of advertisements on the home page are numerically quantified. Finally, there are other elements, such as the display of a privacy statement on the sign-up page, where there were numerous options. In this case, the privacy statement could be a link to another page, a check-box that needs to be checked before the user may continue, or a full display of the privacy statement on the sign-up page.

Table 2. Matrix of design components vs. cultural dimensions.

\begin{tabular}{|l|l|l|l|l|l|}
\hline Components & $\begin{array}{l}\text { Power } \\
\text { Distance }\end{array}$ & $\begin{array}{l}\text { Individuality } \\
\text { Index }\end{array}$ & $\begin{array}{l}\text { Masculinity } \\
\text { vs. } \\
\text { Femininity }\end{array}$ & $\begin{array}{l}\text { Uncertainty } \\
\text { Avoidance }\end{array}$ & $\begin{array}{l}\text { Long Term } \\
\text { Orientation }\end{array}$ \\
\hline Metaphor & & & & & \\
\hline $\begin{array}{l}\text { Mental } \\
\text { Model }\end{array}$ & & & & & \\
\hline Navigation & & & & & \\
\hline Interaction & & & & & \\
\hline Appearance & & & & & \\
\hline
\end{tabular}

Combining the five cultural dimensions as discussed by Hofstede with the five design components results in a 5-by-5 matrix as shown below in Table 2. For each component in the matrix, SNSs from several different countries were compared and contrasted to evaluate the possible influence of culture on their designs. The observations are discussed in the next section.

\section{Analysis of Cultural Dimensions and UI Components}

The following sections discuss Hofstede's cultural dimensions and the user-interface components within them. Examples cite specific SNSs. To clarify some descriptions, visual examples appear from the sites being compared. All cultural dimension and corresponding values mentioned in this section can be referred to in Figure 1.

\subsection{Power Distance: High vs. Low}

\subsubsection{Navigation: User-Identity Authentication}

Following Hofstede's definition of Power Distance, we assume that low powerdistance countries prefer open access, multiple options, and sharable paths. On the other hand, high power-distance countries have a higher use of authentication and passwords, and they prefer prescribed routes and restricted choices. A clear example of this difference can be seen in the sign-up pages of Cyworld, a youth orientated SNS, in the USA and South Korea. The power distance value for the USA (40) is lower than that of South Korea (60). To register on Cyworld USA, one only needs to enter basic credentials and create a password. None of the information entered is 
verified, so it is easy for one to impersonate someone else. On the other hand, Cyworld South Korea verifies identity using a credit card and then requests for authorization by sending a text message to the user's cell phone. Unless both of these steps are completed, an account cannot be created.

\subsection{Collectivism vs. Individualism}

\subsubsection{Metaphors: Public Display of Members' Private Pictures}

Applying Hofstede's theory, we assume metaphors used in collectivist countries might be relationship-oriented and content-oriented, whereas those in individualist countries might be action- or tool-oriented. Given this understanding, it is reasonable to see members' pictures viewable by non-members on the first page of MySpace in the USA (individualist, with a individuality index of 91), because the members typically want to have as many friends as possible on their "friends list". Contrasting this action-oriented objective with that of Mixi in Japan (collectivist, with an individuality index of 46), one can see that no member information is accessible by non-members. An example of the display of members' pictures on MySpace appears in Figure 2, in which the members are labeled as "Cool New People".

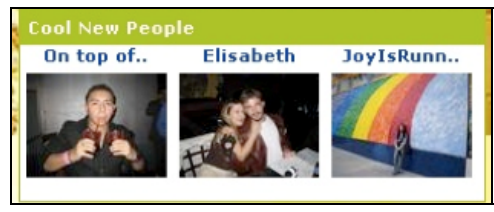

Fig. 2. Display of members' pictures on the front page of MySpace in the USA

\subsubsection{Appearance: Use of Cartoons to Replace Member Pictures}

People from individualistic countries are typically more independent and strive to be unique individuals. In contrast, people from collectivistic countries prefer not to stand out and are more discreet. This difference is apparent when comparing user-profile pictures in Cyworld USA (individuality index of 91) with those of Cyworld Japan (individuality index of 46), as in Figure 3. As can be seen, the user-profile pictures from the USA are of the individuals themselves. However, this treatment is different for Cyworld Japan, in which pictures of animals, toys, or even celebrities are used in a user's profile in place of her/his photo.

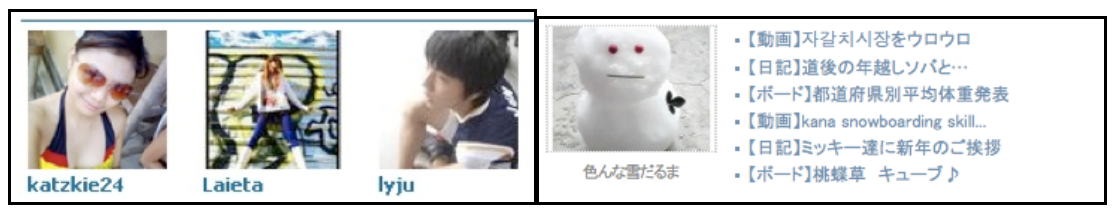

Fig. 3. User profile pictures in Cyworld USA (left) and in Cyworld Japan (right) 


\subsection{Femininity vs. Masculinity}

\subsubsection{Navigation: Limited vs. Variable Choices}

Hofstede's theory on femininity vs. masculinity asserts that more feminine countries would prefer multiple-choices, multi-tasking and polychronic approaches, whereas more masculine countries would prefer limited choices and synchronic approaches. We compare Mixi from Japan (high masculinity rating, with a value of 95) with MySpace from the USA (lower masculinity rating, with a value of 62). Mixi provides its users with a limited amount of options and customizability. The user's homepage features, layout and colors are not changeable. MySpace takes a different approach, where almost every aspect of the user's homepage is customizable. As determined by the user, features such as music, YouTube clips, photos and others can be added or removed from the homepage.

\subsection{Uncertainty Avoidance}

\subsubsection{Metaphors: Use of Icons}

Applying Hofstede's theory about uncertainty, we assume cultures with lower uncertainty avoidance would not shun, and might even prefer, novel, unusual, vague, or abstract references, whereas cultures with a higher amount of uncertainty avoidance might prefer familiar, stable, and clear references to daily life and be more comfortable with representation instead of abstraction. We compare the use of icons by Mixi in Japan (higher uncertainty avoidance, with a value of 92) with that of Fotolog in the USA (lower uncertainty avoidance, with a value of 46) as shown in Figure 4. Notice that Mixi has an icon for every link, whereas Fotolog has none.

\begin{tabular}{|c|c|c|c|}
\hline ( & (日) コミュニティ & Q 友人を探す & 友人を招待 \\
\hline FOTOLOC & UPLOAD ARCHIV & FRIENDS/FAVOF & ES MY ACCOUN \\
\hline
\end{tabular}

Fig. 4. Use of icons in Mixi (Japan) and Fotolog (USA)

\subsubsection{Mental Model: Display of strangers}

Considering the mental model, we expect tolerance for ambiguousness in countries with low uncertainty avoidance. Conversely, we expect simple, explicit, clear articulation in countries with high uncertainty avoidance. Therefore, it is not surprising to see a pane in the user's home page in Facebook (USA, low in uncertainty avoidance) dedicated to "People You May Know" as in Figure 5. Such a feature creates uncertainty as one begins to wonder if they actually know the members featured on this pane. To the authors' knowledge, no Japanese or South Korean SNS implements a similar feature. 


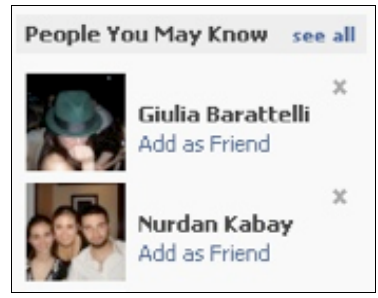

Fig. 5. "People You May Know" feature in Facebook (USA)

\subsubsection{Navigation: Unique Sign-In Page}

Countries with higher uncertainty avoidance tend to prefer clear, explicit articulation and limited choices; whereas countries with lower uncertainty avoidance are more tolerant of implicit structures and complexity. A simple example of this distinction can be seen by comparing the sign-in pages of two business SNSs, Ning in the USA (lower uncertainty avoidance, with a value of 46) and Linknow in South Korea (higher uncertainty avoidance, with a value of 85), as shown in Figure 6. On the first page of Ning, the user is directed to another page to sign in. This link is text-based, small, and on the upper-right-hand corner of the screen. On the other hand, there is a prominent sign-in box on Linknow's first page, a design that clearly reduces ambiguity of navigation.

Sign Up or Sign In / Popular Social Networks

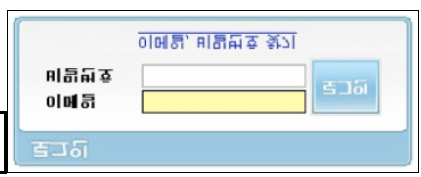

Fig. 6. Sign-in link on Ning (USA) and sign-in box on Linknow (South Korea)

\subsubsection{Appearance: Symmetrical Design}

Countries with high uncertainty avoidance may prefer simple, clear, and consistent UI layout when compared to countries with low uncertainty avoidance. A simple way to analyze this factor is by comparing the layouts of different SNSs. Figure 7 shows the top of the homepage of Linknow in South Korea (higher uncertainty avoidance) with that of Linkedin in the USA (lower uncertainty avoidance). We observe that Linknow

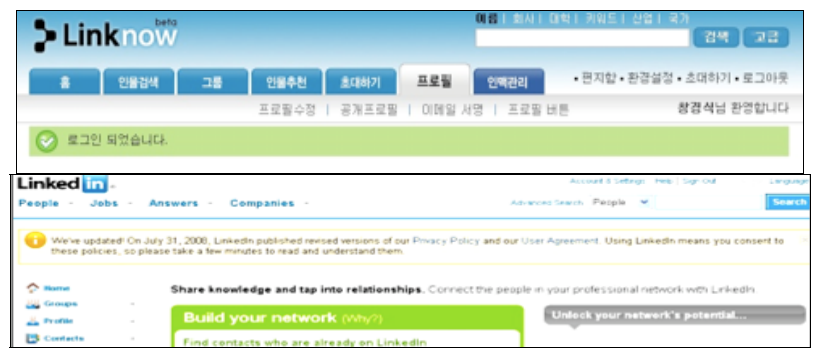

Fig. 7. Symmetrical (Linknow, South Korea) vs. asymmetrical (LinkedIn, USA) design 
has a more structured, symmetrical design with the page header set as tabs. Also, the header is aligned with the main content of the page. In contrast, LinkedIn has a less symmetrical look, as the page header does not align with the main content. Besides that, the components of the page in LinkedIn appear to float in the main content area.

\subsection{Long-Term Time Orientation}

\subsubsection{Mental Model: Purpose / Age Divide}

Hofstede's theory seems to imply that long-term time-oriented countries would more actively pursue the long-term perspective. Given this theory, we can assume that SNSs from long-term time-orientated countries such as Japan and South Korea would cater towards more longer-term relationship building when compared to SNSs from short-term time-orientated countries such as the USA where target audiences are less loyal to a brand. Numerous SNSs from South Korea, a country with high long-term time-orientation, such as Cyworld, IDtail and PlayTalk are promoted to a general audience in which users can establish longer-term relations. In contrast, there is a distinct age divide for SNSs in the United States, a country with relatively lower longterm time-orientation. Disney XD is an SNS designed for preteens, MySpace for teenagers and youths, Facebook for young adults, and Eons for baby boomers. Users can be expected to enter and leave these as their ages, interests, social connections, and preferences change. Also, there are many SNSs that are designed around certain special interests, such as LibraryThing for books lovers. Some of these differences arise from the strong individualist orientation as well as the shorter time perspective of American culture.

Note that a new Chinese SNS site FaceKoo has had some success appealing only to a youth market 1 . This contradiction is explained by the growing shift of culture values in some segments of Chinese society, especially the wealthier, more modernized, more individualistic eastern regions most affected by technology change.

\section{Discussion}

From the analysis above, it becomes obvious that there are numerous cultural artifacts that integrate with the design of SNSs. However, it is important to not over-generalize, and assume that all design elements successful in one of these countries is guaranteed to provide the same results in other countries ranking similarly on Hofstede's cultural dimensions. Katayama 5 gives an example of how Cyworld Japan has failed to take-off especially when compared to Cyworld's huge success in its home country of South Korea. In the article, the Public Relations Manager for Cyworld Japan states "The Japanese tend not to talk about personal topics online." Therefore, Cyworld Japan created friend grouping functions and the option of censoring who can see certain information about the user. Related to the uniqueness of Japanese culture is the success of Mixi in Japan. Mixi is the most popular SNS in Japan with $84.8 \%$ of the market share. Toto of TechCrunch 12 states that one of the important features of Mixi allows Japanese users to maintain a high level of anonymity. This feature, so-called ashi-ato (Japanese for footprint) allows the user to retrace every visitor on his or her profile page, thus improving the feeling of personal security. 
Other examples of SNSs venturing into cultures different from their originating country include Facebook's foray into Asian countries as well as Cyworld's expansion into the United States. An example of Facebook's failure to understand local Japanese culture is apparent when, while in Tokyo, Mark Zuckerberg, the founder and CEO of Facebook mentioned that one of the unique selling points of Facebook is the usage of real names and photos in profiles 13 . However, this selling point may be exactly what the Japanese users are trying to avoid, as reasoned in Section 3.2.2. Cyworld USA implements features that may be better suited for South Korean culture than American culture. Its use of acorns to represent money 6 may be more confusing to users in the United States who may not understand the relationship between acorns and money, as they are more task-orientated.

While this paper provides some insights into apparent cultural differences in SNSs, more research needs to be done to obtain a clearer picture of the cultural artifacts involved in the different SNS sites. One way to move forward in obtaining more information is to complete more cells in the 5 by 5 matrix shown in Table 2 . The inclusion of Europe into the study would also help give a clearer picture of how cultural differences affect patterns observed on SNS sites across the world. Europe was not included in this paper due to a lack of time and funding. Different types of more focused comparisons can be made as well. For example, the differences and similarities between the different Cyworld sites (South Korea, Japan and the United States) can be analyzed to see if any patterns emerge. Another option would be to narrow the focus of the research to one particular category of SNSs such as youth, photo sharing, or music and videos. Finally, a more through option to consider is to use the best-ofbreed cultural dimensions as proposed by Marcus and Baumgartner 11 to replace Hoftstede's cultural dimensions. The best-of-breed dimensions are context, technology, uncertainty avoidance, time perception, and authority conception, in that order. However, more data needs to be obtained from South Korea and Japan if these dimensions are to be used.

\section{Acknowledgements}

The authors acknowledge the assistance of previous Designer/Analysts at the authors' firm, who carried out the original gathering of SNS Website samples and initial analysis of design characteristics: David Chang, Kaoru Kimura, and Hye-min Kim.

\section{References}

1. Gage, D.: Western Ideas, Tailored to East. The San Francisco Chronicle, Technology, January 12, 2009, D1 (2008)

2. Grossman, L.: Computer Literacy Tests: Are You Human? TIME, June 5 (2008),

http://www.time.com/time/magazine/article/

$0,9171,1812084,00$. html

3. Hitwise: MySpace Received 74 Percent of U.S Social Networking Visits for April 2008 (May 6, 2008),

http://www.hitwise.com/press-center/hitwiseHS2004/

social-networking-visits-april.php 
4. Hofstede, G., Hofstede, G.J.: Cultures and Organizations - Software of the Mind. McGraw-Hill, New York (2005)

5. Katayama, L.: Japanese Facebook takes Model T approach. The Japan Times Online, June 25 (2008),

http://search.japantimes.co.jp/cgi-bin/nc20080625a1.html

6. Kirkpatrick, M.: Massive Korean Social Network Cyworld Launches in US. TechCrunch, July 27 (2006),

http: / /www.techcrunch.com/2006/07/27/

this-is-nuts-cyworld-us-opens-for-use/

7. Marcus, A.: Cross-Cultural User-Interface Design Patterns for Mobile Products in Japan, Taiwan, and the USA. Aaron Marcus and Associates, Inc. (2007)

8. Marcus, A., Baumgartner, V.J.: Culture vs. Corporate Global Web UI Design. Aaron Marcus and Associates, Inc. (2004)

9. Marcus, A., Gould, E.W.: Cultural Dimensions and Global Web User-Interface Design: What? So What? Now What? In: Proc. 6th Conference on Human Factors and the Web, University of Texas, Austin, TX, June 19 (2000),

http: //www.tri.sbc.com/hfweb

10. Marcus, A.: Graphical User-Interfaces. In: Helander, M., Landauer, T.K., Prabhu, P.V. (eds.) Handbook of Human-Computer Interaction, ch. 19, pp. 423-444. Elsevier, Amsterdam (1997)

11. Marcus, A., Baumgartner, V.-J.: A practical set of culture dimensions for global userinterface development. In: Masoodian, M., Jones, S., Rogers, B. (eds.) APCHI 2004. LNCS, vol. 3101, pp. 252-261. Springer, Heidelberg (2004)

12. Toto, S.: Japan's Mixi: A Social Network As A Purely Local Phenomenon. TechCrunch, July 20 (2008),

http: / / www. techcrunch.com/2008/07/20/

japans-mixi-a-social-network-as-a-purely-local-phenomenon/

13. Toto, S.: Taking social networks abroad - Why MySpace and Facebook are failing in Japan. TechCrunch, August 3, 2008 (2008),

http: / /www.techcrunch.com/2008/08/03/taking-social-networksabroad-why-myspace-and-facebook-are-failing-in-japan/

14. Web Marketing Guide: Survey on utilization and current situation of SNS (translated). Web Marketing Guide, June 8 (2008),

http: //www.e-research.biz/profile/003437.html 